\title{
Effects and Comprehensive Evaluation of Different Organic Fertilizer Substitution Ratios on Maize Yield, Soil Organic Carbon Fractions, Nutrients and Heavy Metals
}

Hao He

Shihezi University College of Agriculture

Zhenan Hou

Shihezi University College of Agriculture

Sibo Ru

Shihezi University College of Agriculture

Junhua Li ( $\sim$ ljh630703@163.com )

Shihezi University College of Agriculture

\section{Research Article}

Keywords: organic fertilizer substitution, maize yield, SOC fractions, nutrients, heavy metals

Posted Date: July 26th, 2021

DOl: https://doi.org/10.21203/rs.3.rs-676927/v1

License: (c) (1) This work is licensed under a Creative Commons Attribution 4.0 International License.

Read Full License 
$7 \quad *$ Corresponding author: Junhua Li

8

E-mail address: 1jh630703@163.com 832003, China

\section{and heavy metals}

Hao He, Zhenan Hou, Sibo Ru, Junhua Li*

Key Laboratory of Oasis Eco-agriculture, Xinjiang Production and Construction Corps, College of Agriculture, Shihezi University, Shihezi 832003, Xinjiang, China

Corresponding author address: North 4 Rd, College of Agriculture, Shihezi University, Shihezi, Xinjiang

Acknowledgements The authors are thankful to the support of the National Natural Science Foundation of China (31660598, 31360501) and the National Key R\&D Program of China (2017YFD0201808, 2018YFD0200406). We thank all the technicians for their valuable technical support. 


\section{Abstract}

Organic fertilizer substitution technology is an effective measure to solve the excessive application of chemical fertilizers in agricultural production. A pot experiment was set up with 5 treatments: no fertilizer (CK) and organic fertilizer substituting $0 \%(\mathrm{CF}), 8 \%$ (OF8), $16 \%$ (OF16), and 24\% (OF24) of chemical $\mathrm{N}$ fertilizer to analyze their effects on maize yield, soil organic carbon (SOC) and its fractions, carbon pool management index (CPMI), nutrients and heavy metals to provide a scientific basis for safe fertilizer application to maize. This study found that OF8, OF16, and OF24 all increased the content and proportion of SOC and labile organic C (LOC) fractions, CPMI, most of the middle and trace elements, and heavy metals content and their pollution indices in soil and grain compared to CF. Grain was more vulnerable to pollution compared to soil. There was a strong positive correlation between the content of middle and trace elements, and heavy metal, SOC and its fractions (except LLOC), and organic fertilizer substitution ratio, all with no significant correlation with yield. OF8 and OF16 promoted maize growth with a significant increase yield of $35.65 \%$ and $30.28 \%(P<0.05)$, respectively. A comprehensive analysis determined the optimum substitution ratio of $8 \%$ (OF8), which can reduce chemical fertilizer and increase yield, improve soil fertility, low heavy metal pollution risk, is beneficial to promote sustainable agricultural development.

Keywords: organic fertilizer substitution; maize yield; SOC fractions; nutrients; heavy metals 


\section{Introduction}

Maize (Zea mays L.) is the major grain and feed crop and is important to ensure food security and maintain social stability in China. However, excessive application of chemical fertilizer to ensure yield is common in agricultural production, resulting in reduced soil fertility, increased planting costs and environmental pollution, which is detrimental to the sustainable development of agriculture ( $\mathrm{Lu}$ et al. 2020). Therefore, a fertilizer application measure that can ensure crop yields, reduce fertilizer application and environmental pollution is urgently needed to achieve sustainable agricultural development. In recent years, the average annual chemical fertilizer application to maize has been $12 \mathrm{Mt}$, accounting for $20.1 \%$ of total chemical fertilizer application (Xu et al. 2019). Therefore, the reduction in the amount of chemical fertilizers applied to maize production is conducive to the achievement of the "Zero Growth Strategy for Chemical Fertilizers".

Studies have shown that the technology of substituting chemical fertilizer with organic fertilizer is the main way to reduce the application of chemical fertilizer, which is of great significance in ensuring crop yield and reducing agricultural environmental pressure (Liu et al. 2015; Xin et al. 2017; Song et al. 2017). Organic fertilizer substitution technology is a fertilization method that combines the advantages and disadvantages of chemical fertilizer and organic fertilizer. It can timely supply the nutrients needed for crop growth in the early growth stage, and effectively coordinate the contradiction between vegetative growth and reproductive growth in the late growth stage (Redding et al. 2016; Ning et al. 2017), it also increases the content of SOC and further affects the soil physicochemical properties and crop yield (Li et al. 2018; Saikia et al. 2015; Manna et al. 2007).

SOC content cannot explain the change of soil quality and the stability of the organic $\mathrm{C}$ pool, whereas LOC is easy to transform in soil, which is not only the main energy used by microbes, but also the nutrient pool of plants. Although the proportion in the $\mathrm{C}$ pool is very small, it can reflect the small change of soil $\mathrm{C}$ pool in a short time, which is a sensitive index to reflect the change of soil $\mathrm{C}$ pool (Mandal et al. 2020). Therefore, this is a 
more scientific method for using LOC and SOC to jointly evaluate the quality of the organic C pool (Benbi et al. 2015). Loginow et al. (1987) obtained 4 LOC fractions by measuring with 3 concentrations of $\mathrm{KMnO}_{4}(33,167$, $333 \mathrm{mmol} / \mathrm{L}$ ), and Blair et al. (1995) proposed a CPMI based on this, which can reflect the changes of SOC fractions and indicate the changes of soil fertility and soil quality. In recent years, soil LOC and CPMI have gradually become major indicators for evaluating soil quality (Zhang et al. 2021b; Saha et al. 2021; Duval et al. 2019). Studies have shown that a combined application of organic fertilizer and chemical fertilizer increases SOC content and LOC content, thereby improving soil C pool liability (CL) and CPMI (Zhang et al. 2020; Tang et al. 2020). However, there are few reports of the changes to SOC and its fractions, and CPMI under different organic fertilizer substitution ratios.

In recent years, with the development of China's "Farmland Soil Quality Improvement Project" and the implementation of "Zero Growth Strategy for Chemical Fertilizer", the demand and application amount of organic fertilizer showed an increasing trend. Organic fertilizer not only contains rich nutrient elements for plant growth and utilization, but also contains heavy metals elements such as $\mathrm{Cu}, \mathrm{Zn}$, As, etc. which pose a certain threat to the safety of agricultural products, soil, and the ecological environment (Ning et al. 2017; Zaccone et al. 2010). Therefore, the study on the effects of organic fertilizer substitution on agricultural products and soil heavy metals is of guiding significance for the rational application of organic fertilizer in production. Jia (2017) found that substituting $20 \%$ and $40 \%$ of chemical fertilizer with pig manure significantly reduced the contents of $\mathrm{Cu}$, $\mathrm{Zn}, \mathrm{Cd}$, and $\mathrm{Pb}$ in different organs of wheat. While Xia et al. (2020) found that substituting part of chemical fertilizer with pig manure increased the contents of $\mathrm{Cu}, \mathrm{Zn}, \mathrm{As}$, and $\mathrm{Cd}$ in soil, and increased significantly with the increase of the application rate. Ning et al. (2017) found that continued application of commercial organic fertilizer increased the content of $\mathrm{Zn}, \mathrm{Cd}$, and $\mathrm{Cr}$ in soil, while Xie et al. (2016) applied commercial organic fertilizer not only increased the accumulation of $\mathrm{Cr}, \mathrm{Cu}, \mathrm{Zn}, \mathrm{Cd}, \mathrm{Pb}$ and as in soil, but also increased the content 
of heavy metals in agricultural products, and the degree of influence depended on the amount of commercial organic fertilizer applied. Zhang et al. (2021a) found that organic fertilizer substitution increased the content of $\mathrm{Cu}$ and $\mathrm{Zn}$ in wheat for two consecutive years, which was lower than the food standard limit in China. At present, research of organic fertilizer substitution on heavy metals mainly focuses on farm manure, and there is little research on commercial organic fertilizer and its different substitution ratios. Most of the above studies focused on the effects of organic fertilizer substitution on SOC and CPMI or heavy metals, while few attentions were paid to the effects of commercial organic fertilizer substituting part of chemical fertilizer on them.

Based on the previous (2017-2018) field experiment results (He et al. 2021), the pot experiment with different organic fertilizer substitution ratios under the condition of equal N, P, and K was carried out. To explore: (i) the effects on maize growth and yield; (ii) the effects of SOC and its fractions, and CPMI; (iii) the effects of nutrients and heavy metals in maize grain and soil; (iv) and through heavy metals risk assessment of soil and grain and comprehensive analysis, and determine the optimum organic fertilizer substitution ratio. It can provide a theoretical basis for reducing chemical fertilizer and increasing yield, improving soil fertility, low risk, and sustainable scientific organic fertilizer substitution in maize production, to promote the green and sustainable development of agriculture.

\section{Materials and methods}

\section{Study site}

The experiment is located in the Experimental Station of the Agricultural College of Shihezi University, Xinjiang, China. The soil type is calcareous desert soil (Calcaric Fluvisol), and the basic physicochemical properties of the soil are $\mathrm{pH} 7.96$, SOC $5.52 \mathrm{~g} / \mathrm{kg}$, total nitrogen $(\mathrm{N}) 0.65 \mathrm{~g} / \mathrm{kg}$, available phosphorus (AP) 12.38 $\mathrm{mg} / \mathrm{kg}$, available potassium (AK) $149.86 \mathrm{mg} / \mathrm{kg}$.

\section{Materials}




\section{Experimental design}

Before the start of the experiment (early April 2019), the pot experimental soil was selected from the 0-20

$\mathrm{cm}$ soil of the experimental station, and the fresh soil was air-dried and screened with a sieve of $5 \mathrm{~mm}$ to remove

stones, rhizomes, and other sundries. The compactness of the soil was the same as that of the field soil when the

weighed fertilizer was mixed with $10.0 \mathrm{~kg}$ soil and packed into a plastic pot. Five treatments were set up: no

fertilizer (CK) and organic fertilizer substituting 0\% (CF, conventional fertilization), 8\% (OF8), 16\% (OF16), 
Table 1 Fertilization schemes for different treatments (g/pot)

\begin{tabular}{|c|c|c|c|c|c|c|c|c|c|c|c|}
\hline \multirow{3}{*}{ Treatment } & \multirow{3}{*}{$\begin{array}{c}\text { OFSR } \\
(\%)\end{array}$} & \multicolumn{6}{|c|}{ Base fertilizer } & \multirow{3}{*}{$\frac{\text { Topdressing }}{\mathrm{N}}$} & \multirow{2}{*}{\multicolumn{3}{|c|}{ Total nutrient contents }} \\
\hline & & \multicolumn{3}{|c|}{ Chemical fertilizer } & \multicolumn{3}{|c|}{ Organic fertilizer } & & & & \\
\hline & & $\mathrm{N}$ & $\mathrm{P}_{2} \mathrm{O}_{5}$ & $\mathrm{~K}_{2} \mathrm{O}$ & $\mathrm{N}$ & $\mathrm{P}_{2} \mathrm{O}_{5}$ & $\mathrm{~K}_{2} \mathrm{O}$ & & $\mathrm{N}$ & $\mathrm{P}_{2} \mathrm{O}_{5}$ & $\mathrm{~K}_{2} \mathrm{O}$ \\
\hline CK & - & 0 & 0 & 0 & 0 & 0 & 0 & 0 & 0 & 0 & 0 \\
\hline $\mathrm{CF}$ & 0 & 1.20 & 1.80 & 0.60 & 0 & 0 & 0 & 1.80 & 3.00 & 1.80 & 0.60 \\
\hline $8 \% \mathrm{OF}$ & 8 & 0.96 & 1.54 & 0.53 & 0.24 & 0.26 & 0.07 & 1.80 & 3.00 & 1.80 & 0.60 \\
\hline $16 \% \mathrm{OF}$ & 16 & 0.72 & 1.27 & 0.46 & 0.48 & 0.53 & 0.14 & 1.80 & 3.00 & 1.80 & 0.60 \\
\hline $24 \% \mathrm{OF}$ & 24 & 0.48 & 1.01 & 0.39 & 0.72 & 0.79 & 0.21 & 1.80 & 3.00 & 1.80 & 0.60 \\
\hline
\end{tabular}

Note: Organic fertilizer substitution ratio in different treatments was calculated as follows: OFSR $(\%)=$

$\underline{\text { Organic fertilizer } \mathrm{N} \text { contact }}$

\section{Sample collections and chemical determination}

Before the start of the experiment, the mixed soil samples were air-dried and sieved to determine the basic 
132

133

134

135

136

137

138

139

140

141

142

143

follows:

$\operatorname{MLOC}(\mathrm{g} / \mathrm{kg})=(\mathrm{HLOC}+\mathrm{MLOC})-\mathrm{HLOC}$

$\operatorname{LLOC}(\mathrm{g} / \mathrm{kg})=\mathrm{LOC}-(\mathrm{HLOC}+\mathrm{MLOC})$

$\operatorname{ROC}(\mathrm{g} / \mathrm{kg})=\mathrm{SOC}-\mathrm{LOC}$

The proportion of SOC fractions $(\%)=$ SOC fraction $/ \mathrm{SOC} \times 100$

2.6. C pool related indices

C pool related indices include CL, C pool liability index (CLI), C pool index (CPI), CPMI, which are calculated according to Blair et al. (1995) using the following formula:

$\mathrm{CLI}=\mathrm{CL}_{\text {(organic fertilizer substituting treatment) }} / \mathrm{CL}_{(\mathrm{CK})}$

$\mathrm{CL}=\mathrm{LOC} / \mathrm{ROC}$

$\mathrm{CPI}=\mathrm{SOC}_{(\text {organic fertilizer substituting treatment) }} / \mathrm{SOC}_{(\mathrm{CK})}$

$\mathrm{CPMI}=\mathrm{CPI} \times \mathrm{CLI} \times 100$

\section{Assessment methods of heavy metals pollution}

The total amount of heavy metals is a common index to evaluate the degree of heavy metals pollution (Tandy et al. 2009). The single factor index method and Nemerow comprehensive pollution index methods are often used to evaluate the heavy metals pollution of soil and agricultural products (Zhang et al. 2017). Single factor index method calculation formula:

$P_{i}=C_{i} / P_{i}$

Where $P_{\mathrm{i}}$ is the heavy metals pollution index, $C_{i}$ is heavy metals content; $S_{i}$ is the limit standard of heavy metals content in soil and grain, referring to China's latest limit standard for soil pollution (GB 15618-2018) and food safety (GB 2762-2017) (Table 2). $P_{i} \leq 1$ is non-pollution level, $1<P_{i} \leq 2$ is light pollution level, $2<P_{i} \leq 3$ is medium pollution level, and $P_{i}>3$ is heavy pollution level. 
Table 2 Limit standards of China of heavy metals content in soil and grain

\begin{tabular}{cccccccccc}
\hline \multirow{2}{*}{ Type } & \multirow{2}{*}{$\begin{array}{c}\text { Standard } \\
\text { of China }\end{array}$} & & \multicolumn{6}{c}{ Heavy metals content $(\mathrm{mg} / \mathrm{kg})$} \\
\cline { 3 - 8 } & & $\mathrm{Cu}$ & $\mathrm{As}$ & $\mathrm{Cd}$ & $\mathrm{Cr}$ & $\mathrm{Pb}$ & $\mathrm{Ni}$ \\
\hline Soil (pH>7) & GB 15618-2018 & 300.0 & 100.0 & 25.0 & 0.6 & 250.0 & 170.0 & 190.0 \\
Grain & GB 2762-2017 & - & 10.0 & 0.5 & 0.1 & 1.0 & 0.4 & - \\
\hline
\end{tabular}

Where $P_{N}$ is the Nemerow comprehensive pollution index; $P_{i}$ ave and $P_{i \text { max }}$ are the average and maximum moderate pollution; $P_{N}>3.0$ is the serial pollution (Wu et al. 2020).

\section{Statistical analysis}

Data analysed using SPSS 21.0 and then plotted with GraphPad Prism 7.0 and Origin 2018. The statistical methods were one-way analysis of variance and Duncan's test $(P<0.05)$. All figures were combined and processed with Adobe Illustrator CS6.

\section{Results}

\section{Analysis of maize growth and yield}

At V6, the accumulation of dry matter, N, P, K of maize in different treatments were OF8 > CF > OF16 >

OF24 > CK. At the beginning of VT, OF16 was better than CF, and the accumulation of dry matter, N, P, K of maize in different treatments were $\mathrm{OF} 8>\mathrm{OF} 16>\mathrm{CF}>\mathrm{OF} 24>\mathrm{CK}$ (Fig. 1). At R6, with the increase of organic 
172

173

174

175

176

177

178

179

180

181

$31.38 \%-7.11 \%, 25.25 \%-6.57 \%, 18.64 \%-9.83 \%$, respectively; the yield, $\mathrm{N}, \mathrm{P}, \mathrm{K}$ accumulation of grain significantly increased $(P<0.05)$ by $35.65 \%-30.28 \%, 38.89 \%-31.67 \%, 29.17 \%-26.39 \%, 33.87 \%-22.48 \%$, respectively (Fig. 1). Therefore, a suitable organic fertilizer substitution ratio (OF8 and OF16) can promote maize dry matter accumulation and nutrient absorption, thereby increasing yield.
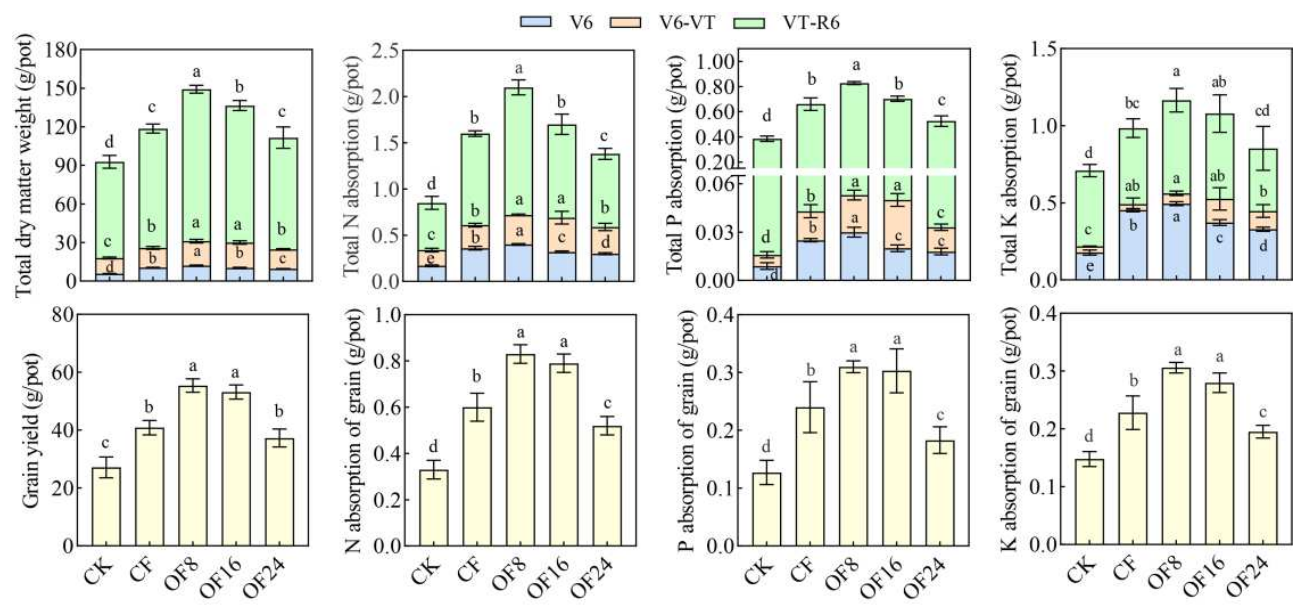

Fig. 1 Effects of different organic fertilizer substitution ratios on growth and yield of maize. The different small letters in the

picture show a significant difference between treatments $(P<0.05)$, the same below.
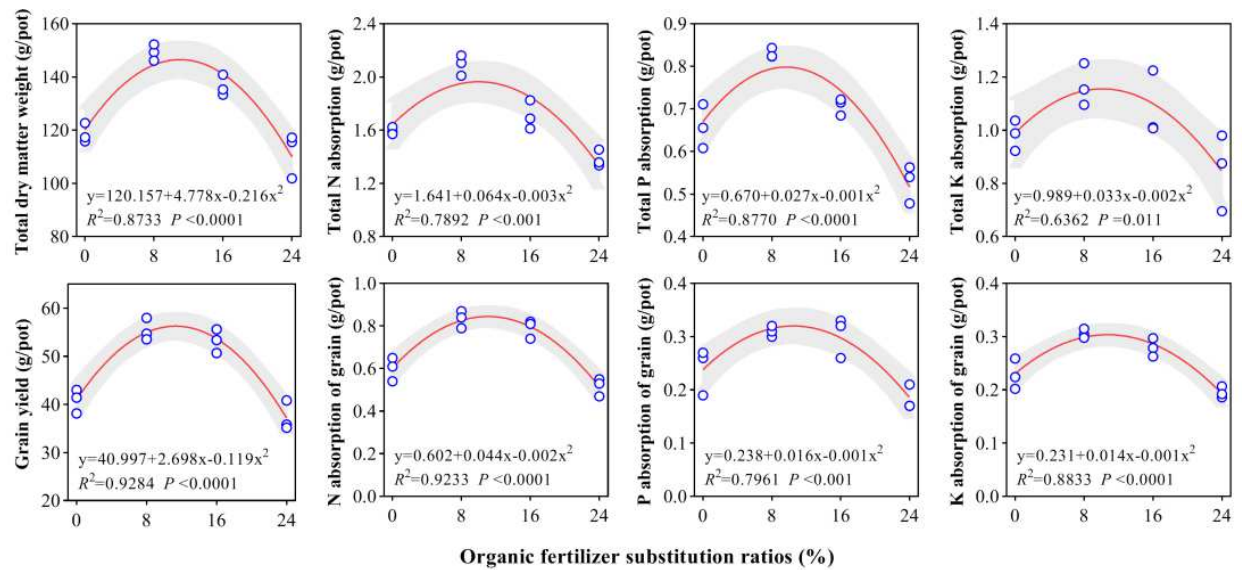

Organic fertilizer substitution ratios $(\%)$

Fig. 2 Regression analysis of different organic fertilizer substitution ratios and maize indexes

\section{Analysis of SOC and its fractions}

During the whole growth stage (V6, VT and R6), compared with CF, OF8, OF16 and OF24 significantly $(P$ $<0.05$ ) increased the content of LOC by $25.92 \%-40.39 \%, 22.73 \%-29.96 \%, 15.37 \%-26.23 \%$, respectively, by 
184

185

186

187

188

189

190

191

192

193

194

195

196

197

increasing the content of different LOC fractions (HLOC, MLOC, and LLOC); the content of ROC increased by $-2.90 \%-6.84 \%, 4.93 \%-16.47 \%, 8.10 \%-12.85 \%$, respectively; the content of SOC increased by $4.08 \%-14.97 \%$, 9.88\%-20.22\%, 12.06\%-18.32\%, respectively $(P<0.05)$, in which SOC and LOC were OF24 $>$ OF16 > OF8 > CF > CF (Fig. 3-A). The increase of SOC and its fractions content will inevitably lead to the change of its fractions proportion, among them, OF8, OF16, and OF24 compared with CF, the LOC/SOC by $20.98 \%-22.11 \%$, $8.10 \%-11.69 \%, 3.16 \%-8.58 \%$, respectively; the ROC/SOC decreased by $6.71 \%-7.07 \%, 3.12 \%-4.50 \%$, 1.20\%-3.26\%, respectively (Fig. 3-B). Therefore, organic fertilizer substitution treatment can increase the content and proportion of SOC and LOC fractions.
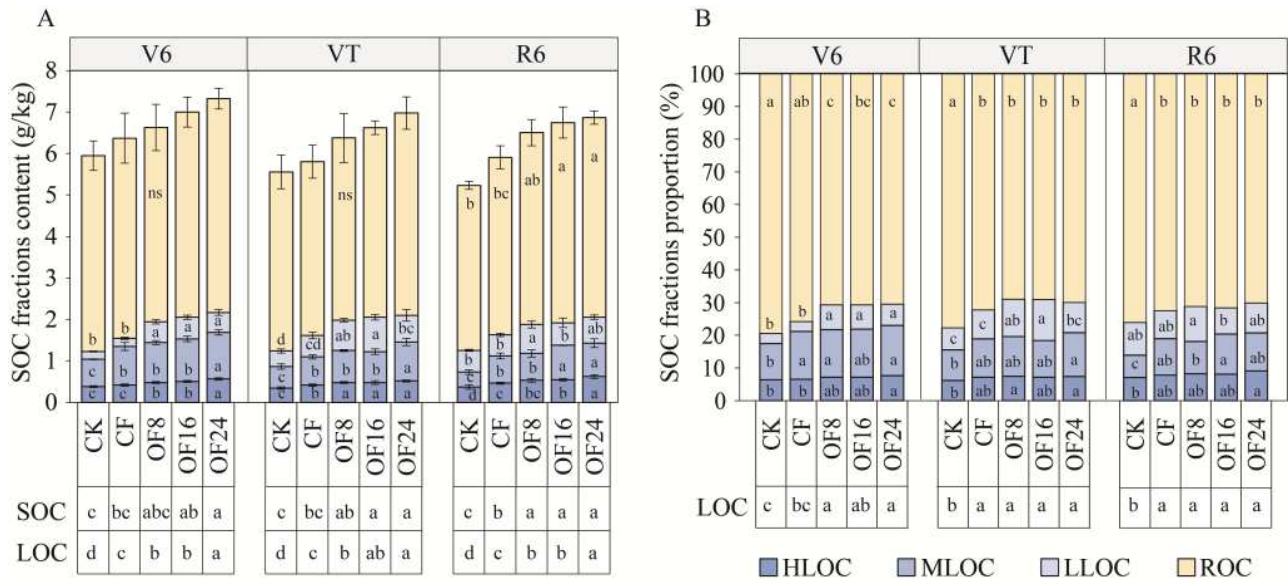

Fig.3 Effects of organic fertilizer substitution ratios on the content (A) and proportion (B) of SOC and its fractions. The accumulation sum of different blue columns is the LOC fractions content, and the accumulation sum of all columns is the SOC content.

\section{Analysis of soil $\mathbf{C}$ pool related indices}

Organic fertilizer substitution treatment increased the $\mathrm{C}$ pool related indices in maize growth stage (V6, VT and R6) (Fig. 4). OF8, OF16 and OF24 compared with CF, the CL increased by 25.00\%-31.25\%, 10.26\%-17.95\%, 5.26\%-13.16\%, respectively (Fig. 4-A); the CLI increased by $24.80 \%-30.40 \%, 11.11 \%-17.04 \%$, 4.96\%-11.57\%, respectively (Fig. 4-B); the CPI increased by 4.67\%-14.95\%, 9.52\%-20.00\% $(P<0.05)$, 
A

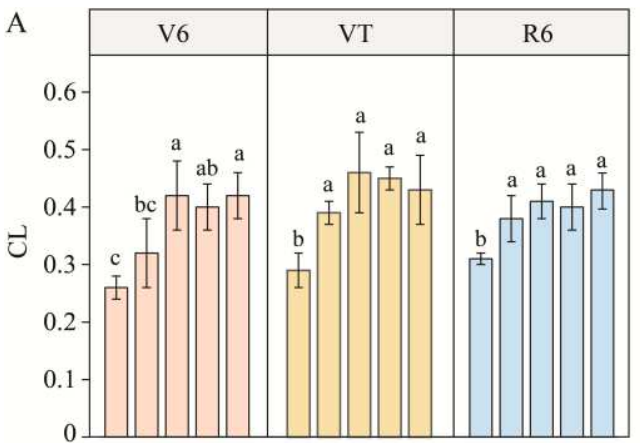

$\mathrm{C}$

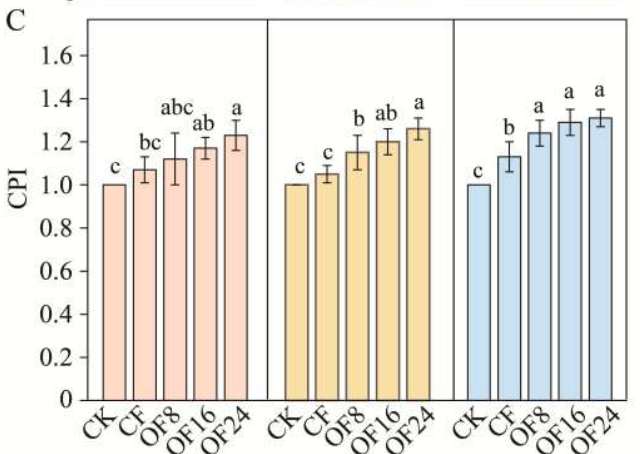

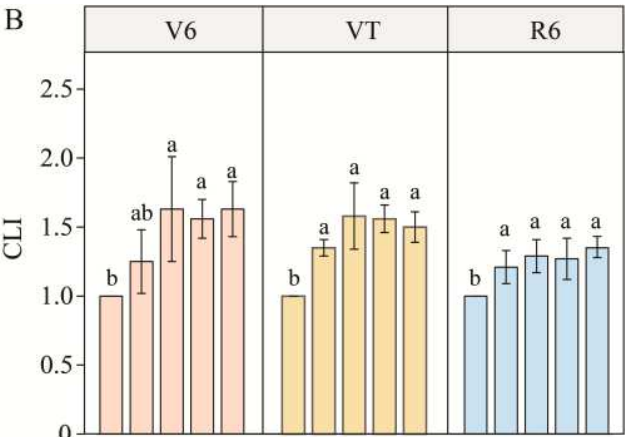

$\mathrm{D}$

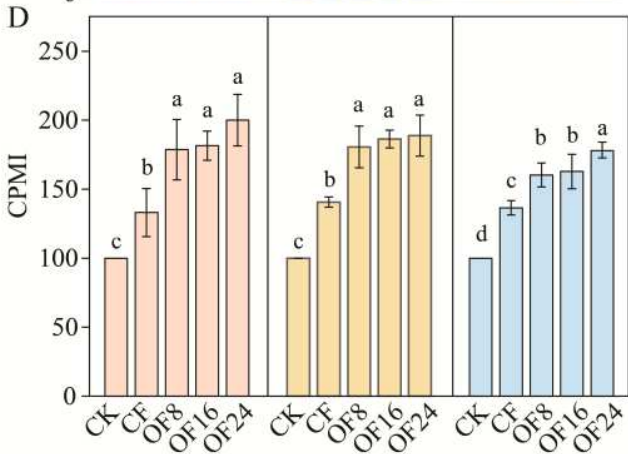

Fig. 4 Effects of different organic fertilizer substitution ratios on soil $\mathrm{C}$ pool related indices

\section{Correlation analyses of SOC and its fractions, C pool related indices, organic fertilizer substitution}

ratio, and yield

There was a significant positive correlation $(P<0.05)$ between all SOC fractions (except LLOC) and SOC.

MLOC, ROC were not significantly positively correlated with LLOC $(P>0.05)$, and the other SOC fractions

indicators have a significant positive correlation $(P<0.05)$ (Fig. 5-A). SOC and LOC fractions were significantly positively correlated with CL, CLI, CPI, and CPMI $(P<0.05)$. ROC was significantly positively correlated with CPI $(P<0.05)$, and ROC was significantly negatively correlated with CL $(P<0.05)$ (Fig. 5-C). SOC and its fractions, $\mathrm{C}$ pool related indices (CL, CLI, CPI, and CPMI) were significantly positively correlated $(P<0.05)$ 
A

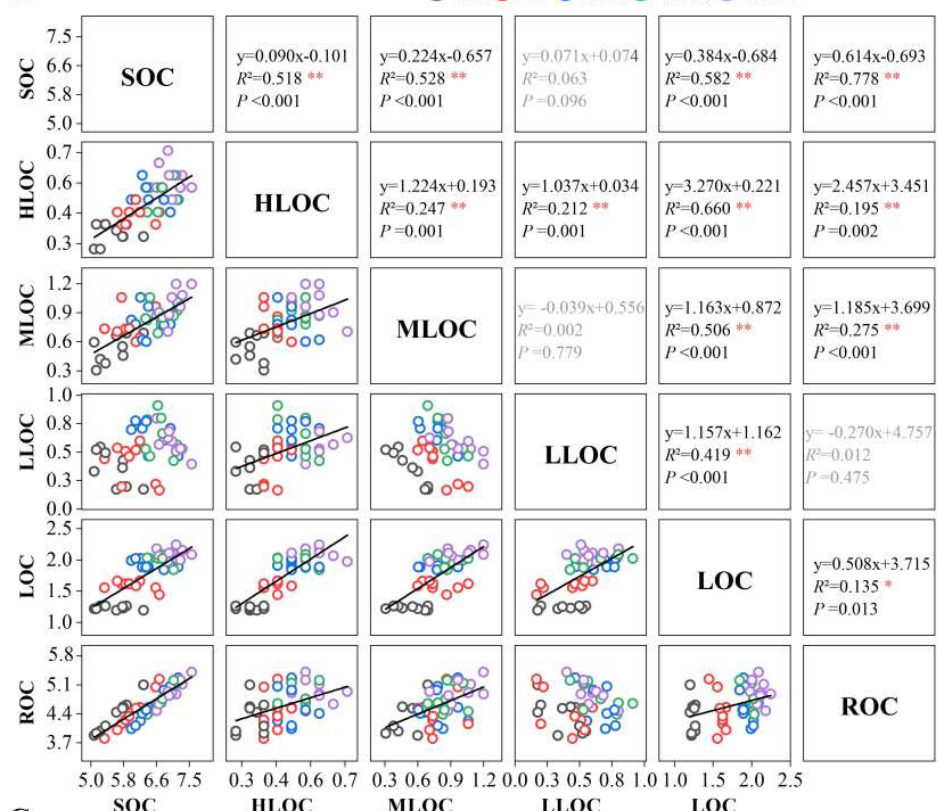

C

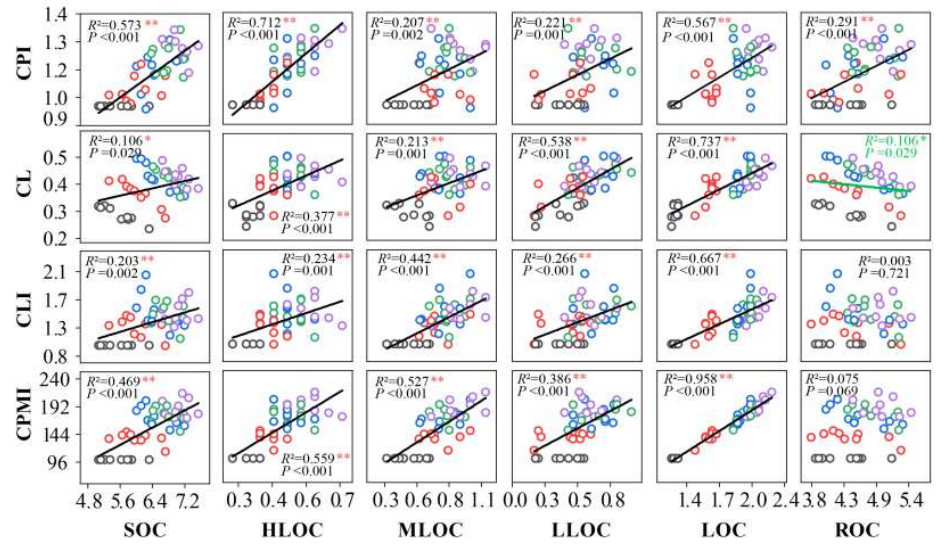

B

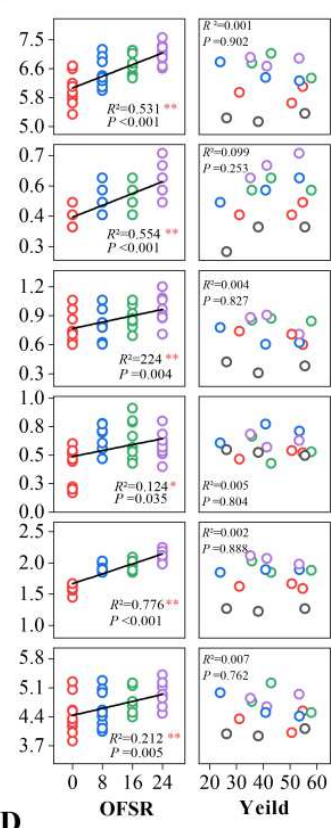

D

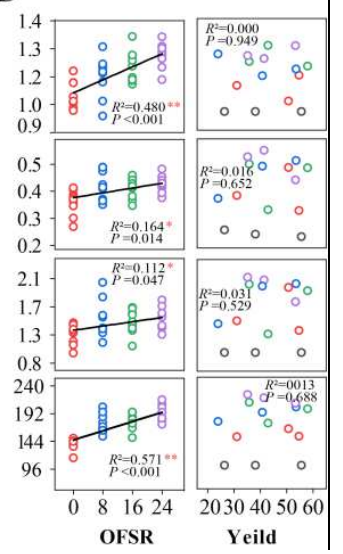

Fig.5 Correlation analysis of SOC fractions (A), organic fertilizer substitution ratios (B), C pool related indices (C), and yield

217 (D). In this figure, $*, P<0.05, *, P<0.01$. OFSR is the organic fertilizer substitution ratios, in which $0,8,16$ and 24 are CK,

OF8, OF16 and OF24, respectively.

\section{Analysis of nutrients and heavy metals in soil and maize grain}

The organic fertilizer substitution treatment obviously improved the content of most of the trace elements 

a significant positive correlation $(P<0.05)$ with organic substitution ratio (Fig. 6-A). For the soil, OF8, OF16, ratio (Fig. 6-B). In grain and soil, the nutrients and heavy metals with a significant positive correlation $(P<0.05)$ with organic fertilizer substitution ratios were also significantly positively correlated with SOC and its fractions (except LLOC) (Fig. 6).

Maize yield was positively correlated $(P<0.05)$ with grain $\mathrm{N}, \mathrm{P}$ content, and soil $\mathrm{N}$ content, while there was no significant correlation $(P>0.05)$ with the content of middle and trace elements, and heavy metals. This indicates that the effect of $\mathrm{N}, \mathrm{P}$ on yield was greater than that of middle and trace elements under the condition of organic fertilizer substitution, while some soil heavy metals would affect maize yield and grain heavy metals content. The clustering results showed that the nutrients and heavy metals contents of both soil and grain from the different treatments were divided into three groups: (i) $\mathrm{CK}$, (ii) $\mathrm{CF}$ and OF8, (iii) OF16 and OF24 (Fig. 6). 

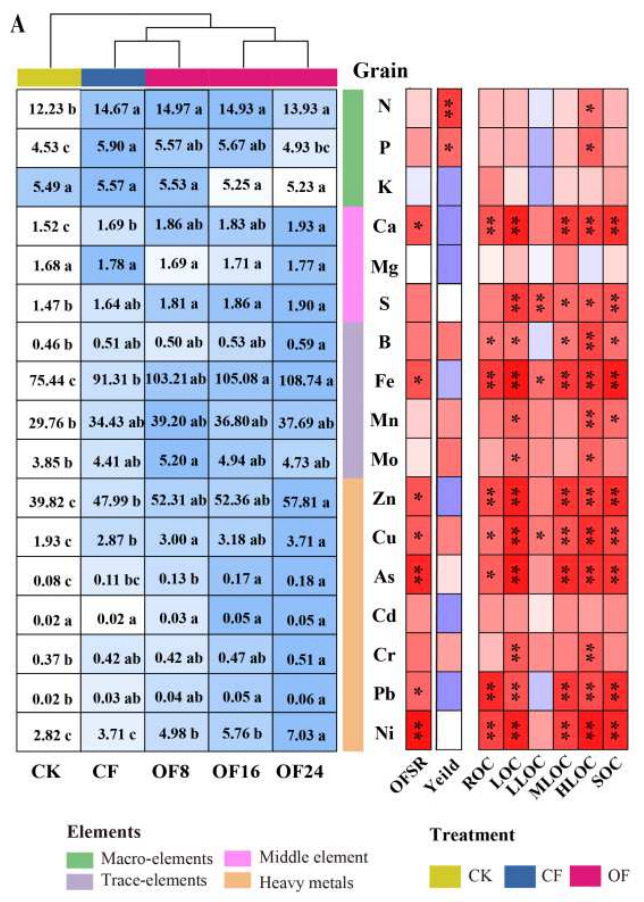

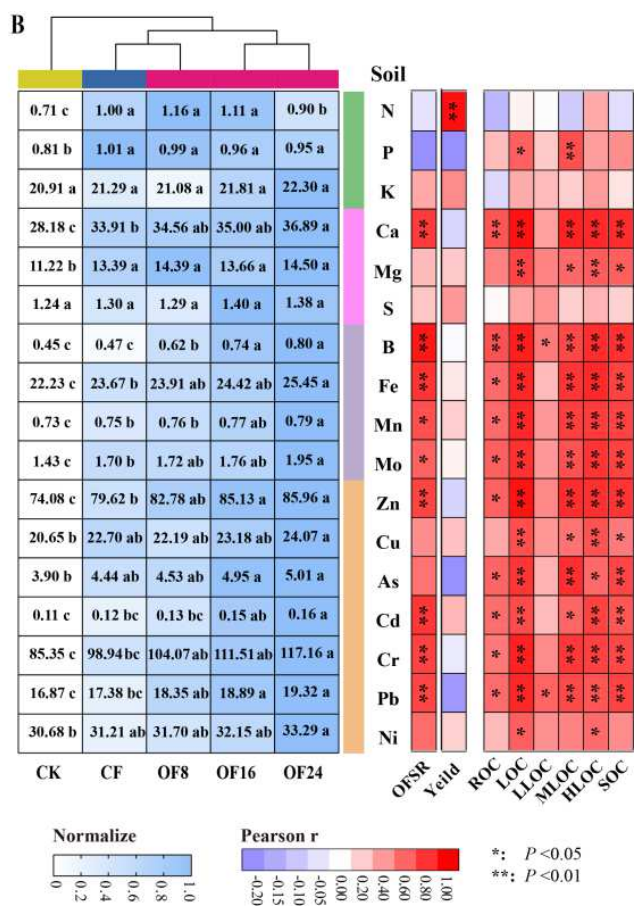

240 Fig. 6 Effects of different treatments of nutrients and heavy metals in grain (A) and soil (B) and their correlation with organic

241 fertilizer substitution ratios, yield, and SOC fractions. The units for macro (N, P, K) and middle elements $(\mathrm{Ca}, \mathrm{Mg}, \mathrm{S})$ are

$\mathrm{g} / \mathrm{kg}$, and for trace elements (Mo, B, Fe, Mn) and heavy metals (Cu, $\mathrm{Zn}, \mathrm{Cd}, \mathrm{Cr}, \mathrm{Pb}, \mathrm{As}, \mathrm{Ni})$ are mg/kg. *, $P<0.05, *, P<0.01$,

OFSR is the organic fertilizer substitution ratio.

\section{Evaluation of heavy metals pollution in maize grain and soil}

The single factor index of heavy metals in soil and grain of each treatment ranged from 0.100 to 0.470 , and

compared with CF, increased by $5.57 \%-2.55 \%, 4.06 \%-16.56 \%$, respectively. 

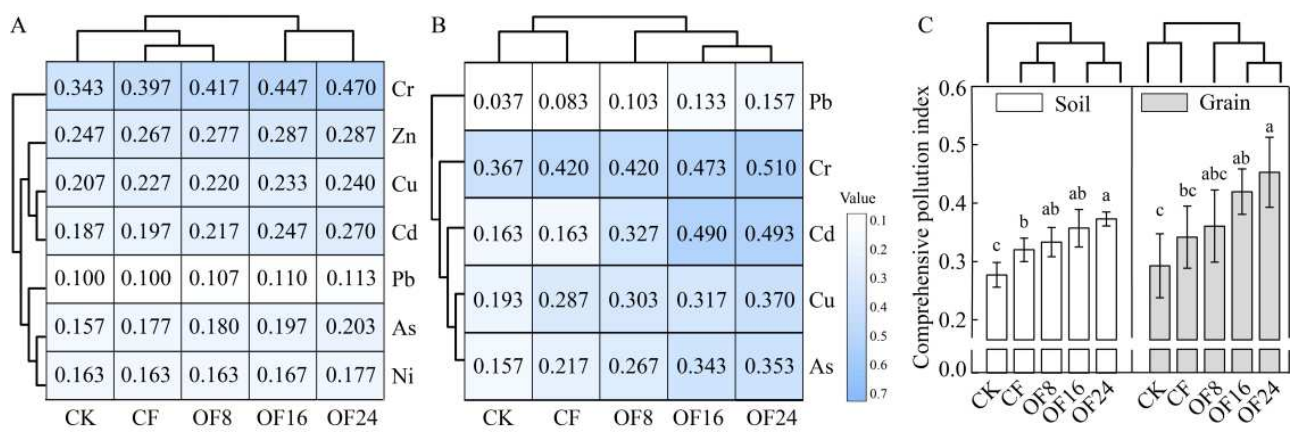

Fig. 7 Evaluation of heavy metals pollution in grain and soil under different treatments

\section{Discussion}

SOC is an important component of the soil $\mathrm{C}$ pool, which promotes crop growth and improves soil quality. 
271

application reduced SOC and LOC content (Li et al. 2018b). CPMI can sensitively reflect the dynamics of the soil $\mathrm{C}$ pool and reveal changes in soil quality, and the defining formulas show that CL, CLI, CPI, and CPMI are a set of interrelated indicators (Mandal et al. 2020). In this study, there was a significant positive correlation between CPMI, SOC and LOC fractions content, and organic fertilizer substitution ratios $(P<0.05)$, and the increase of their contents would inevitably lead to the increase of CL, CLI, and CPI, leading to a significant increase of CPMI $(P<0.05)$, all of which showed OF2 $>$ OF16 $>$ OF8 $>$ CF. This is consistent with the law of SOC and its fractions, then it indicates that organic fertilizer substitution ratios are an important factor in its influence on SOC and its fractions, and CPMI.

In general, OF8, OF16, OF24 effectively increased SOC and its fractions content, and CPMI, which was beneficial to improve soil fertility and quality, but had no significant correlation with maize yield. Maize yield has a significant positive correlation with grain $\mathrm{N}, \mathrm{P}$ content, and soil $\mathrm{N}$ content $(P<0.05)$, but has no significant correlation with middle and trace elements, and heavy metals content of grain and soil (Fig. 6). This is because the increase in organic fertilizer substitution ratios in this study under equal $\mathrm{N}, \mathrm{P}$, and $\mathrm{K}$ conditions inevitably led to an increase in the amount of organic fertilizer and a decrease in the amount of chemical fertilizer, reducing the soil AN, AP, AK and increasing the heavy metals content of soil and grain, which was detrimental to maize growth and yield increase, thus each indicator of maize is related to organic fertilizer substitution ratios in a quadratic function (Fig. 2). However, suitable organic fertilizer substitution ratios (OF8 and OF16) can coordinate the balanced supply of organic and inorganic nutrients to meet the early crop growth on time, and effectively coordinate the relationship between nutrient and reproductive growth in the late reproductive stage, promoting maize dry matter accumulation and nutrient uptake, thus increasing maize yield, which is consistent with some studies (Gai et al. 2018; Li et al. 2017; Zhang et al. 2016; Geng et al. 2019). In addition, HLOC was significantly positively correlated with grain $\mathrm{N}, \mathrm{P}$ content $(P<0.05)$ (Fig. 6-A), which indicated that organic 
fertilizer substitution promoted $\mathrm{N}$ and $\mathrm{P}$ uptake in the grain by increasing HLOC content, thereby increasing maize yield, and that some studies have been limited to considering the effect of the LOC level on plant growth and development (Li et al. 2020).

Organic fertilizer is not only rich in nutrient elements, but also contains a certain amount of heavy metals.

Organic fertilizer application and its amount are key factors affecting the content of heavy metals such as $\mathrm{Cr}, \mathrm{Cu}$, $\mathrm{Zn}, \mathrm{Cd}, \mathrm{Pb}$ and $\mathrm{As}$ in soil and agricultural products (Wu, et al. 2020), therefore, clarifying the effect of different organic fertilizer substitution ratios of heavy metals in soil and grain can provide a safe fertilizer application for maize provides a scientific basis. This study found that organic fertilizer substitution treatments obviously increased the content of middle and trace elements, and heavy metals in maize grain and soil, and were positively correlated with the organic fertilizer substitution ratios (Fig. 6). This indicates that their contents were affected by the amount of organic fertilizer applied, which is consistent with the results of some studies (Ning et al. 2017; Xie et al. 2021; Zhang et al. 2021a). Through correlation analysis, it was found that most of the middle and trace elements (except grain $\mathrm{Mg}$, soil S), and heavy metals had a significant positive correlation with SOC and its fractions (except LLOC), with the correlation being stronger for the soil than for grain. This indicates that an increase in the content of SOC and its fractions in OF8, OF16, and OF24 inevitably leads to an increase in the content of middle and trace elements, and heavy metals in soil and grain. This may be because SOC contains a variety of functional groups, such as carboxyl, alcohol hydroxyl, enol hydroxyl, etc. which affect the migration and accumulation of heavy metals in the soil through sorption, chelation, and complexation, thus affecting the accumulation of heavy metals in maize grain (Zhao et al. 2014; Leszczynska and Kwiatkowska, 2015).

For this study, OF8, OF16, and OF24 increased the content of SOC and its fractions, CPMI, the middle and trace element content. However, it also increased the heavy metals content in soil and grain. Therefore, while actively promoting the application of organic fertilizer substitution technology, it is important to be alert to the 
risk of heavy metals pollution that may be brought about by organic fertilizer application, and to carry out soil and grain heavy metals pollution risk evaluation, which will be of guidance for scientific fertilizer application to maize in agricultural production. This study found that OF8, OF16, and OF24 obviously increased the single factor index and comprehensive pollution index of heavy metals in soil and grain, and neither reached pollution levels. While grain was more susceptible to heavy metals pollution than soil. However, the risk of heavy metals pollution increased with organic fertilizer substitution ratios, indicating that organic fertilizer application was the main cause of heavy metals content in soil and grain. This is consistent with Wu et al. (2020) study, while Ilker Ugulu et al. (2021) found that the application of cattle and poultry manure treatment reduced the risk of heavy metals compared with chemical fertilizer treatment.

The plant and soil effects should be considered comprehensively to determine the suitable organic fertilizer substitution ratio. In this study, in terms of plants, OF8 and OF16 significantly increased the yield $(P<0.05)$, among them, grain nutrients and heavy metals content of OF8 is similar to CF, and its heavy metals pollution risk is also lower than OF16 and OF24 (Figs. 1, 6-7). In terms of soil, organic fertilizer substitution has increased the SOC fractions and CPMI, the soil nutrient and heavy metals content of OF8 are similar to that of CF, and its heavy metals pollution risk is also lower than OF16 and OF24 (Figs. 3-4, 6-7). After comprehensive soil and plant effects, $8 \%$ is determined as the optimum organic fertilizer substitution ratio (Fig. 8), which is consistent with our previous field research (He et al. 2021). Therefore, the optimum organic fertilizer substitution ratio is helpful to prevent the risk of heavy metals pollution in soil and agricultural products, and promote the sustainable and healthy development of agricultural production. 


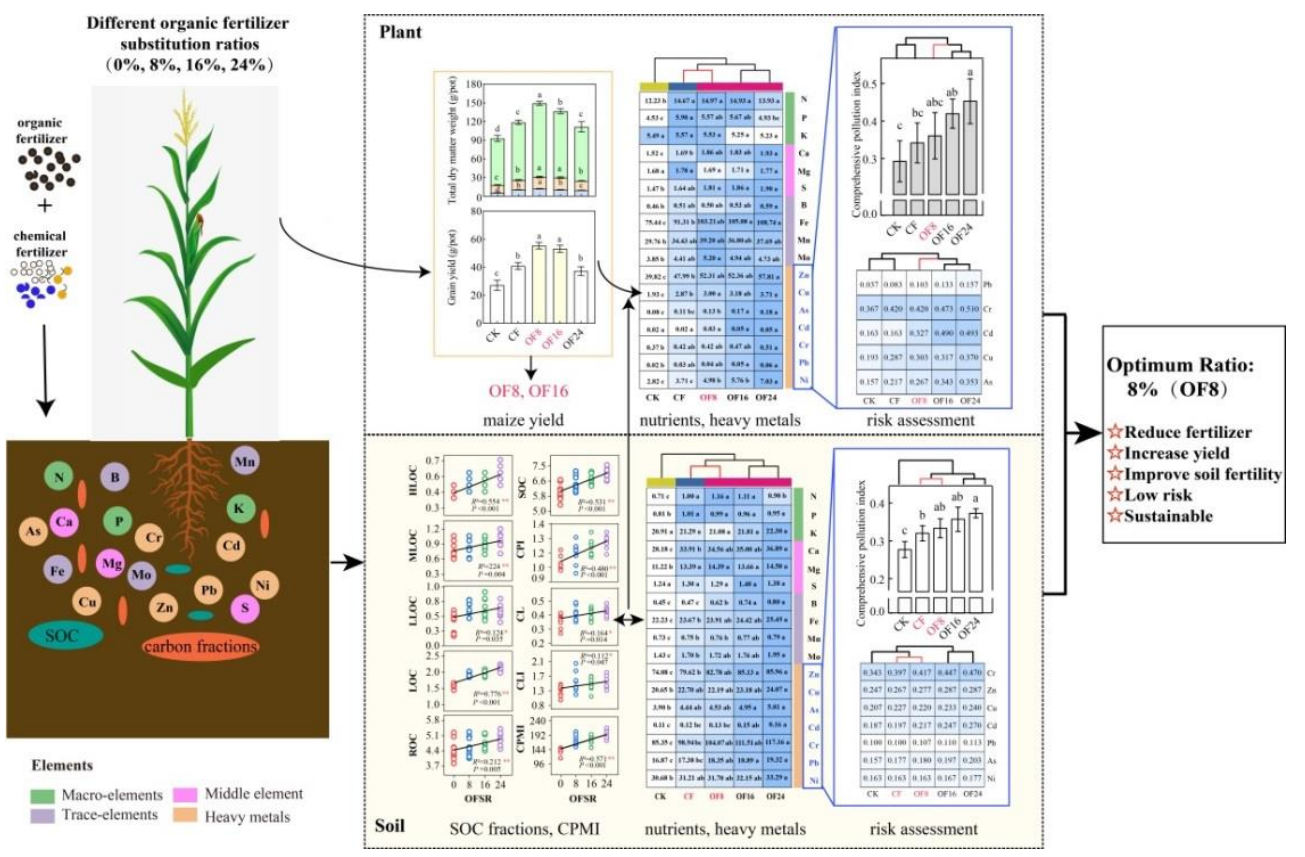

Fig. 8 Determination of the optimum organic fertilizer substitution ratio

\section{Conclusion}

This study found that organic fertilizer substitution treatments (OF8, OF16, and OF24) all increased the content and proportion of SOC and LOC fractions, CPMI, most of the middle and trace elements, and heavy metals content and their pollution indices in soil and grain compared to conventional fertilization (CF). Grain was more vulnerable to pollution than soil, but none of them exceeded the limits standard of China. SOC and its fractions (except LLOC), middle and trace elements, and heavy metals in soil and grain were all significantly positively correlated with organic fertilizer substitution ratios, and none was significantly correlated with yield.

Suitable organic fertilizer substitution ratios (OF8 and OF16) significantly increased yield by $35.65 \%$ and $30.28 \%$ 
348 Funding This research was supported by the National Natural Science Foundation of China (31660598,

349 31360501) and the National Key R\&D Program of China (2017YFD0201808, 2018YFD0200406).

Authors' contributions Hao He: Conceptualization, Data curation, Formal analysis, Writing - original draft,

Writing - review and editing. Zhenan Hou: Writing - review and editing, Supervision. Sibo Ru: Methodology,

Acknowledgements The authors are thankful to the support of the National Natural Science Foundation of

\section{Declarations}

Ethical approval and consent to participate Not applicable.

359 Consent for publication All authors have read and approved the final version of the manuscript for publication.

Availability of data and materials All data generated or analyzed during this study are included in this published article.

Competing interests The authors declare no competing interests. 


\section{References}

Bao SD (2000) Soil and agricultural chemistry analysis, 3rd edn. China Agriculture Press, Beijing

Benbi DK, Brar K, Toor AS, Singh P (2015) Total and labile pools of soil organic carbon in cultivated and undisturbed soils in northern India. Geoderma 237-238:149-158. https://doi: 10.1016/j.geoderma.2014.09.002

Blair GJ, Lefroy RDB, Lisle L (1995) Soil carbon fractions based on their degree of oxidation, and the development of a carbon management index for agricultural systems. Aust J Agr Res 46(7):1459-1466. https://doi: 10.1071/ar9951459

Duval M, Martinez JM, Galantini JA (2019) Assessing soil quality indices based on soil organic carbon fractions in different long-term wheat systems under semiarid conditions. Soil Use Manage 36(1):71-82. https://doi: $10.1111 /$ sum. 12532

Gai XP, Liu HB, Liu J, Zhai LM, Yang B, Wu SX, Ren TZ, Lei QL, Wang HY (2018) Long-term benefits of combining chemical fertilizer and manure applications on crop yields and soil carbon and nitrogen stocks in North China Plain. Agri Water Manag 208:384-392. https://doi: 10.1016/j.agwat.2018.07.002

Geng YH, Cao GJ, Wang LC, Wang SH (2019) Effects of equal chemical fertilizer substitutions with organic manure on yield, dry matter, and nitrogen uptake of spring maize and soil nitrogen distribution. Plos One 14(7):e0219512. https://doi: 10.1371/journal.pone.0219512

He H, Zhang YT, Wei CZ, Li JH (2021) Effects of different organic fertilizer replacement rates on maize growth and soil fertility under equal nutrient conditions. Journal of Nuclear Agricultural Sciences 35(2):0454-0461. https://doi: 10. 11869/j.issn.100-8551. 2021.02.0454

Jia, F (2017) Effects of swine manure application on heavy metals in soils and crops under rice wheat rotation system. Sichuan agricultural university, Chengdu City, Sichuan Province, China. 1-64 
387

388

Leszczynska D, Kwiatkowska MJ (2011) Effect of organic matter from various sources on yield and quality of plant on soils contaminated with heavy metals. Ecological Chemistry and Engineering S-Chemia I Inzynieria Ekologiczna S 18(5):501-507

Li CX, MA SC, Shao Y, Ma ST, Zhang LL (2018a) Effects of long-term organic fertilization on soil microbiologic characteristics, yield and sustainable production of winter wheat. J Integr Agric 17(1):210219. https://doi: 10.1016/S2095-3119(17)61740-4

Li H, Feng WT, He XH, Zhu P, Gao HJ, Sun N, Xu MG (2017) Chemical fertilizers could be completely replaced by manure to maintain high maize yield and soil organic carbon (SOC) when SOC reaches a threshold in the Northeast China Plain. J Integr Agric 16(4):937-946. https://doi: $10.1016 / \mathrm{S} 2095-3119(16) 61559-9$

Li J, Wen YC, Li XC, Li YT, Yang XD, Lin ZA, Song ZZ, Cooper J, Zhao BQ (2018b) Soil labile organic carbon fractions and soil organic carbon stocks as affected by long-term organic and mineral fertilization regimes in the North China Plain. Soil Tillage Res 175:281-290. https://doi: 10.1016/j.still.2017.08.008

Li ZQ, Zhang X, Xu J, Cao K, Wang JH, Xu CX, Cao WD (2020) Green manure incorporation with reductions in chemical fertilizer inputs improves rice yield and soil organic matter accumulation. J Soils Sediments 20(7):2784-2793. https://doi: 10.1007/s11368-020-02622-2

Liu HT, Li J, Li X, Zheng YH, Feng SF, Jiang GM (2015) Mitigating greenhouse gas emissions through replacement of chemical fertilizer with organic manure in a temperate farmland. Sci. Bull 60(6):598-606. https://doi: 10.1007/s11434-014-0679-6

Loginow W, Wisniewski W, Gonet SS, Ciescinska B (1987) Fractionation of organic carbon based on susceptibility to oxidation. Polish Journal of Soil Science 20(1):47-52

Lv FL, Song JS, Giltrap D, Feng YT, Yang XY, Zhang SL (2020) Crop yield and $\mathrm{N}_{2} \mathrm{O}$ emission affected by 
Mandal M, Kamp P, Singh M (2020) Effect of long term manuring on carbon sequestration potential and dynamics of soil organic carbon labile pool under tropical rice-rice agro-ecosystem. Commun Soil Sci Plant Anal 51(4): 468-480. https://doi: 10.1080/00103624.2020.1718690

Manna MC, Swarup A, Wanjari RH, Mishra B, Shahi DK (2007) Long-term fertilization, manure and liming effects on soil organic matter and crop yields. Soil Tillage Res 94:397-409. https://doi:

Saikia P, Bhattacharya SS, Baruah KK (2015) Organic substitution in fertilizer schedule: impacts on soil health,

Saha M, Das M, Sarkar A (2021) Distinct nature of soil organic carbon pools and indices under nineteen years of rice based crop diversification switched over from uncultivated land in eastern plateau region of India. Soil Tillage Res 207(1):104856. https://doi: 10.1016/j.still.2020.104856

Redding MR, Lewis R, Kearton T, Smith O (2016) Manure and sorbent fertilisers increase on-going nutrient availability relative to conventional fertilisers. Sci Total Environ 569:927-936. https://doi: 10.1016/j.scitotenv.2016.05.068

photosynthetic efficiency, yield and assimilation in wheat grown in alluvial soil. Agric Ecosyst Environ 203:102-109. https://doi: 10.1016/j.agee.2015.02.003

Song K, Xue Y, Zheng XQ, Lv WG, Qiao HX, Qin Q, Yang JJ (2017) Effects of the continuous use of organic manure and chemical fertilizer on soil inorganic phosphorus fractions in calcareous soil. Sci Rep 7:1164. 
432

Tandy S, Healey JR, Nason MA, Williamson JC, Jones DL (2009) Remediation of metal polluted mine soil with compost: co-composting versus incorporation. Environ Pollut 157(2): 690-697. https://doi: 10.1016/j.envpol.2008.08.006

Tang HM, Xiao XP, Li C, Pan XC, Cheng KK, Shi LH, Li WY (2020) Short-term responses of soil organic carbon and its labile fractions to different manure nitrogen input in a double-cropping rice field. J Agric Sci 158(1-2):119-127. https://doi: 10.1017/S0021859620000398

Tessier A, Campbell PGC, Bisson M (1979) Sequential of extraction procedure for the speciation of particulate trace metals. Analytical Chemistry 51(7): 844-851. doi: 10.1021/ac50043a017

Ugulu I, Ahmad K, Khan ZI, Munir M, Wajid K, Bashir H (2020) Effects of organic and chemical fertilizers on the growth, heavy metal/metalloid accumulation, and human health risk of wheat (Triticum aestivum L.). Environ Sci Pollut Re 28(10):12533-12545. https://doi: 10.1007/s11356-020-11271-4

Wu R, Liu SJ, Sun H, Du Y, Ma L (2020) Effects of long-term chemical fertilizer application with different organic fertilizers on accumulation of heavy metals in soil and maize. Journal of Plant Nutrition and Fertilizer 26(11):2010-2019. https://doi: 10.11674/zwyf.20194

Xia WJ, Zhang LF, Liu ZB, Zhang WW, Lan XJ, Liu XM, Liu J, Liu GR, Li ZZ, Wang P (2021) Effects of long-term application of chemical fertilizers and organic fertilizers on heavy metals and their availability in reddish paddy soil. Environmental Science 42(5):2469-2479. https://doi: 10.13227/j.hjkx.202008094

Xie GX Wang JW, Zhang D, Ni ZY, Ye YQ, Xu J (2016) Effects of commercial organic fertilizer application on crop yield and heavy metals accumulation in soil and agricultural products. Chinese Agricultural Science Bulletin 32(29):97-104

Xin XL, Qin SW, Zhang JB, Zhu AN, Yang WL, Zhang XF (2017) Yield, phosphorus use efficiency and balance 

response to substituting long-term chemical fertilizer use with organic manure in a wheat-maize system. Field Crops Res 208:27-33. https://doi: 10.1016/j.fcr.2017.03.011

Xu Y, Yang F, Zhang WF, Meng YD, Jiang Y (2019) Status and problems of chemical fertilizer application in crop plantations of China from 2014 to 2016. Journal of Plant Nutrition and Fertilizers 25(1):11-21. https://doi: 10.11674/zwyf.18073

Yang R, Su YZ, Wang T, Yang Q (2016) Effect of chemical and organic fertilization on soil carbon and nitrogen accumulation in a newly cultivated farmland. J Integr Agric 15(3):658-666. https://doi: $10.1016 / \mathrm{S} 2095-3119(15) 61107-8$

Zaccone C, Di Caterina R, Rotunno T, Quinto M (2010) Soil-farming system-food-health: Effect of conventional and organic fertilizers on heavy metal $(\mathrm{Cd}, \mathrm{Cr}, \mathrm{Cu}, \mathrm{Ni}, \mathrm{Pb}, \mathrm{Zn})$ content in semolina samples. Soil Tillage Res 107(2):97-105. https://doi: 10.1016/j.still.2010.02.004

Zhang GB, Song KF, Miao X, Huang Q, Ma J, Gong H, Zhang Y, Paustian K, Yan XY, Xu H (2021a) Nitrous oxide emissions, ammonia volatilization, and grain-heavy metal levels during the wheat season: effect of partial organic substitution for chemical fertilizer. Agric Ecosyst Environ 311(129-132):107340. https://doi: 10.1016/j.agee.2021.107340

Zhang LG, Chen X, Xu YJ, Jin MC, Gao HJ, Chu WY, Mao JD, Thompson ML (2020) Soil labile organic carbon fractions and soil enzyme activities after 10 years of continuous fertilization and wheat residue incorporation. Sci Rep 10:11318. https://doi: 10.1038/s41598-020-68163-3

Zhang XB, Nan S, Wu LH, Xu MG, Bingham IJ, Li ZF (2016) Effects of enhancing soil organic carbon sequestration in the topsoil by fertilization on crop productivity and stability: evidence from long-term experiments with wheat-maize cropping systems in China. Sci Total Environ 562:247-259. https://doi: 10.1016/j.scitotenv.2016.03.193 
Zhang YN, Chu CL, Li T, Xu SG, Liu L, Ju MT (2017) A water quality management strategy for regionally protected water through health risk assessment and spatial distribution of heavy metal pollution in 3 marine reserves. Sci Total Environ 599:721-731. https://doi: 10.1016/j.scitotenv.2017.04.232

Zhang YR, Li Yu, Liu YL, Huang XC, Zhang WA, Jiang TM (2021b) Responses of soil labile organic carbon and carbon management index to different long-term fertilization treatments in a typical yellow soil region. Eurasian Soil Sci 54(4):605-618. https://doi: 10.1134/S1064229321040189

Zhao YC, Yan ZB, Qin JH, Xiao ZW (2014) Effects of long-term cattle manure application on soil properties and soil heavy metals in corn seed production in Northwest China. Environ Sci Pollut Re 21(12):7586-7595. https://doi: 10.1007/s11356-014-2671-8 